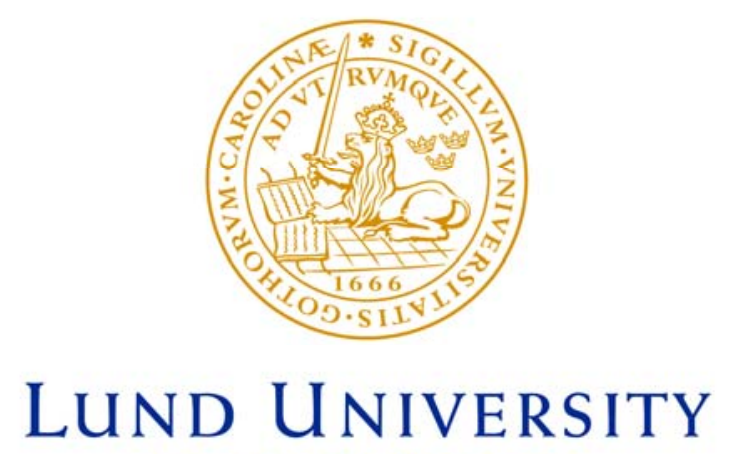

Faculty of Medicine

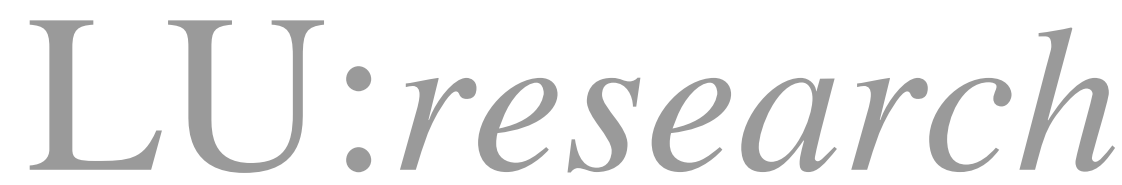

Institutional Repository of Lund University

This is an author produced version of a paper published in International journal of nursing studies. This paper has been peer-reviewed but does not include the final publisher proof-corrections or journal pagination.

Citation for the published paper:

Wann-Hansson, Christine and Rahm Hallberg, Ingalill and Klevsgard, Rosemarie and Andersson, Edith.

"The long-term experience of living with peripheral arterial disease and the recovery following revascularisation: A qualitative study"

International journal of nursing studies, 2007, Issue: Feb 3.

\title{
http://dx.doi.org/10.1016/j.ijnurstu.2006.11.006
}

Access to the published version may require journal subscription.

Published with permission from: Elsevier 


\section{The long-term experience of living with peripheral arterial disease and the recovery following revascularization: a qualitative study}

\section{Christine Wann-Hansson, Ingalill Rahm Hallberg, Rosemarie Klevsgård, Edith Andersson}

Christine Wann-Hansson, PhD, RN, is a Senior Lecturer, School of Health and Society, Malmö University, Sweden.

Ingalill Rahm Hallberg, PhD, RNT, is a Professor, Department of Health Sciences, Lund University and The Vårdal Institute, The Swedish Institute for Health Sciences, Sweden. Rosemarie Klevsgård, PhD, RNT, is a Senior Lecturer, Department of Health Sciences, Lund University, Sweden.

Edith Andersson, PhD, RNT, is a Senior Lecturer, Department of Health Sciences, Lund University, Sweden.

Correspondence to: Christine Wann-Hansson, School of Health and Society, Malmö

University, SE-205 06 Malmö, Sweden

Tel: +46-40-6657430 Fax: +46-40-6658100

E-mail: christine.wann.hansson@hs.mah.se

Category: Original article

Running head: Long-term experience of recovery after revascularization 


\section{ABSTRACT}

Background: The long-term experience of living with peripheral arterial disease (PAD) and the durability of improvements after revascularization are sparsely described in the literature. The primary goal of medical treatment and nursing care for PAD is to provide relief of symptoms, improve quality of life and prevent the progression of arterial disease and cardiovascular complications. A majority are elderly with a significantly increased risk of myocardial infarction, stroke and cardiovascular death. Which can limit mobility and functional status even in the absence of ischaemic claudication, rest pain or ulceration after a successful revascularization.

Objectives: To illuminate the long-term experience of living with peripheral arterial disease and the recovery following revascularizations.

Methods: Fourteen patients were interviewed 6 months and 21/2 years after revascularization. The transcribed texts were analysed using manifest and latent content analysis.

Results: The long-term experience of living with PAD meant gradually becoming aware of having a chronic disease. This was interpreted in the following themes, representing the transition from being in an acute phase of PAD to the recovery after revascularization and entering a chronic phase of PAD: (I) “becoming better but not cured”; (II) “recapturing control over life”; (III) "reappraising meaning in life”.

Conclusions: Becoming aware of having a chronic disease results in a need to adapt to and accept permanent restrictions in daily life. The findings showed that revascularizations offer several benefits, however when PAD symptoms were relieved other ailments became discernable, which reflects the complex course of PAD and atherosclerotic disease. Moreover, several critical points and events such as other concurrent diseases, unrealistic hope for recovery, the complex course of PAD and atherosclerotic disease complicated the transition process towards health and well-being. 


\section{What is already known about this topic?}

Peripheral arterial disease is a chronic condition and a majority of the patients are elderly with a significantly increased risk of myocardial infarction, stroke and cardiovascular death.

Living with peripheral arterial seriously impairs the quality of life, especially due to problems such as pain, reduced energy and restricted mobility.

Quality of life improves after revascularization during the first year if major amputation is avoided and the circulation is sustained with a functioning graft.

\section{What this paper adds}

Understanding about how patients with peripheral arterial disease experience recovery following revascularizations in a long-term perspective.

Knowledge about the benefits from revascularization and a realistic view of what patients with PAD may expect from vascular treatments.

Revelation that other concurrent diseases, unrealistic hope for recovery and the complex course of peripheral arterial disease complicate the transition towards health and well-being.

Awareness of the need for complementary interventions such as information and education, that is vital in order to assist patients with peripheral arterial disease and their families in accepting the chronic disease over time. 


\section{INTRODUCTION}

The long-term experience of living with peripheral arterial disease (PAD) and the durability of improvements after revascularization are sparsely described in the literature. Traditionally vascular surgery outcome studies have reported bypass graft patency, limb salvage and patient survival (Dormandy and Rutherford, 2000). In recent years, however, quality of life has also been reported (Klevsgård et al., 2001; Thorsen et al., 2002). PAD is a chronic condition with a prevalence of $14.5 \%$ in people $>70$ years old (Selvin and Erlinger, 2004). The primary goals of medical treatment and nursing care for this group of patients are to provide relief of symptoms, improve quality of life and prevent the progression of arterial disease and cardiovascular complications (Treat-Jacobson and Walsh, 2003). This means that despite a successful revascularization the extensive comorbid conditions could limit mobility and functional status also in the absence of ischaemic claudication, rest pain or ulceration (Dormandy and Rutherford, 2000). Knowledge about how these patients experience recovery over a longer period and what leads to independent living may facilitate understanding of the impact of treatment and the need for complementary efforts.

\section{Literature review}

Several quality of life studies have shown that a revascularization results in less pain, improved physical mobility and sleep 12 months after treatment (Klevsgård et al., 2001; Thorsen et al., 2002). Although, studies with a longer follow-up time are few, one study showed a significant decreased physical mobility in patients with critical ischaemia four years after treatment (Wann-Hansson et al., 2005a). Nicoloff et al (1998) showed that only 16 of 112 patients achieved the ideal surgical result with long-term symptom relief and maintenance of functional status after infrainguinal bypass. Many patients had an ongoing need for care, including repeated surgery and hospitalizations for wound care. Most patients had also 
persistent or recurrent symptoms until their death (Nicoloff et al., 1998). Gibson and Kenrick (1998) interviewed patients with PAD and found that these patients not always were aware of the chronic nature of the disease and felt disappointment over the persisted pain since they had expected to recover. Studies reflecting what it means to live with PAD in a long-term perspective could therefore contribute to a more realistic view of what patients with PAD may expect from a vascular intervention.

Chronic illness refers to an experience of multiple problems that may change but not vanish by undergoing surgical procedure or medical therapy. This results in limitations of the individual's ability to continue his or her lifestyle with alterations in daily activities (Miller, 1992). PAD has conceptual similarities to many other recognized chronic diseases but despite this PAD is rarely acknowledged in the chronic illness literature. A reason for this can be the context of revascularization, which reflects an acute cure-orientated field. However, goals of acute care do not explicitly address the needs and concern of chronically ill patients. When and how patients with PAD incorporate the consequences of illness into their lives is therefore of great interest.

Transition can be defined as a passage or movement from one state, condition or place to another and includes several essential properties; awareness, engagement, change and difference, time span and critical points and events (Chick and Meleis, 1986; Meleis et al., 2000). The concept focuses on the experience of transition during a life crisis. In recent years research on life transitions has focused specifically on the experience of transition in chronic illness as a constant process including being attentive to bodily responses, careful planning of daily activities and of learning new strategies (Koch and Kralik, 2001, Kralik et al., 2004, 2006). However, little is known about how patients with PAD adjust to their bodily changes over time and knowledge about what possibly could facilitate the transition process for patients with PAD is needed. 
The aim of this study was to illuminate the long-term experience of living with peripheral arterial disease and recovery following revascularizations.

\section{METHODS}

\section{Sample}

Fourteen participants with PAD were interviewed 6 months and 21/2 years after their initial revascularization. The mean age at inclusion was 75 years (range 61-85 years) and 9 were men. During the follow-up period of $2 \frac{1}{2} 2$ years five participants underwent more than one revascularization (Table 1). The inclusion criteria were patients: (1) who had undergone an active vascular intervention; (2) who were able to participate in interviews (no serious mental or communicative problems); (3) who had not undergone a major lower limb amputation. The sample was recruited from a previous study including twenty-four participants with PAD, which were interviewed before undergoing angiography at a university hospital in southern Sweden. These interviews reflecting the acute phase of PAD are presented elsewhere (WannHansson et al., 2005b). Out of the initial sample of 24 participants, 5 died, 3 were treated conservatively and 2 participants had undergone a major amputation, leaving 14 participants fulfilling the inclusion criteria for the present study. Six months is a common follow-up interval in PAD functional outcome studies (Abou-Zamzam et al., 1997; Chetter et al., 1998; Klevsgård et al., 2000) and 21/2 years was considered as a suitable time for the second interview to minimize the risk of attrition since the calculated 5-year mortality rate is $30 \%$ in patients with PAD (Dormandy and Rutherford, 2000). 


\section{Data collection}

Participants meeting the inclusion criteria received written and oral information about the study and informed consent was obtained. The participants had the option to withdraw from the study at any time. Information about time of treatment, type of treatment and the course of events during the 6 months and 21/2 years was collected from the medical records of the included participants. The Ethics Committee of the Medical Faculty, Lund University, approved the study (LU 333-01).

The interviews were conducted in the participants' homes by the first author and were based on the idea from Mishler (1986). According to Mishler (1986) interviews should be seen as forms of discourse constructed jointly by interviewers and informants, where the meaning of questions and answers is contextually grounded. The interviewer started by asking the participant to speak openly about what had happened during the last 6 months (interview A) and 2⿺辶⿸厃𠄌 years (interview B) after their initial revascularization. The interviews focused on: everyday life after treatment, changes in everyday life before and after treatment, possible benefits of the treatment, and how to handle remaining problems in daily life due to the PAD. The rationale for interviewing twice during the $2 \frac{1}{2} 2$ years after revascularization was to gain knowledge of the recovery process and to understand what it means to live with PAD over a longer period. The study included a total of 28 tape-recorded interviews, each lasting 45-90 minutes.

\section{Data analysis}

The texts from the interviews were analysed using manifest and latent content analysis (Berg, 2001; Graneheim and Lundman, 2004). Manifest content analysis focuses on the most obvious and straightforward meanings of a text, whereas latent content analysis is extended to an interpretative reading and captures the deep structural meaning of the text (Berg, 2001). In 
the current study, manifest content analysis was used to describe the long-term experience of living with PAD, which was physically present in the text. Latent content analysis was used to illuminate the meaning of living with PAD and recovery after revascularization.

The analysis process started with a so-called naive reading in order to understand each interview as a whole. Meaning units, that is words or phrases carrying a meaning of importance for the research question, were delimited. Thereafter each meaning unit was evaluated by the questions "what is it about?", “what does it mean?” and "what effect does it have?” Characteristic features of the text were the participant's descriptions of their recovery, remaining or new symptoms and their adjustments and adaptation to living with a chronic disease over time. Three authors (CWH, RK and EA) independently performed the first reading and meaning units dealing with the same content were grouped into categories. Within each category similar statements were analysed critically and questioned, read and compared to arrive at a reasonable interpretation and identify themes and sub-themes. The category system was then discussed with the second author (IRH) and adjustments were made to establish a degree to which the categories covered all aspects of the texts and main theme, themes and sub-themes were decided. Finally, a systematic comparison was made between the meaning units dealing with the same content from the first (A) and the second (B) interview to detect possible changes over time.

\section{FINDINGS}

The long-term experience of living with peripheral arterial disease meant becoming gradually aware of having a chronic disease. The informants' wove the past, present and future into their descriptions and it was apparent that having a chronic disease meant revising expectations over time. By looking into the past it became discernable that the problems 
caused by PAD had existed for several years. Moreover, at present it had become clear that the recovery process probably had come to an endpoint and further improvements were not to expect. Finally, looking into the future reflected wishes and hopes of being able to keep the present condition and not become worse. The awareness of having a chronic disease was interpreted in the following themes representing the transition from being in an acute phase of PAD, to the recovery after revascularization and entering a chronic phase: (I) "becoming better but not cured”; (II) “recapturing control over life”; (III) "reappraising meaning in life”. These themes were related to each other by means of internal variations shown in seven subthemes.

\section{Becoming better but not cured}

Having a vascular intervention when suffering from PAD meant relief from symptoms and a beginning to feel better, but it also revealed new or existing ailments. Expectations of recovery were high at the interview six months after revascularization, but were marked by a more realistic view over time as a gradual awareness of having a chronic disease was reached. From the narratives of the recovery period after revascularization the following sub-themes emerged: beginning to feel better, learning to live with remaining circulation problems in the legs, revealing other ailments.

\section{Beginning to feel better}

The greatest benefits of revascularizations were the relief from pain, the ability to sleep again and wounds healing. Getting back the ability to move and walk independently was also highly valued. The recovery period was, however, experienced as unpredictable and often very long. Although, the first feelings of relief contributed to hope and confidence, later on feelings of disappointment and despair could be just as great when the symptoms sometimes recurred. 
However, the improvements stabilized over time and worries about the severe symptoms coming back decreased. The present condition was put in a favourable light when comparisons between then and now were made. Expressions such as "my leg is now perfect" or “it feels $100 \%$ good” occurred, despite obvious remaining circulation problems.

"Of course you become a different person in that you're allowed to sleep. You maybe don’t need so many hours but...” (8A)

"When you compare what it was like before the operation then it was terrible. I had such pains that I didn't even know my name but now I mean, I think it works rather well and it is like I said, sometimes I'm in pain and sometimes not and it's like I said now when I'm talking to you, I don't feel anything but it can come just like out of the blue sometimes.” (5B)

\section{Learning to live with remaining circulation problems in the legs}

Having vascular treatment meant relief from severe symptoms, but also coming to an endpoint with a need to accept some remaining circulation problems in the legs. Hope for further improvements were greater during the interview after six months and were characterized by more moderate expectations after $2 \frac{1}{2} 2$ years. As one man said after 6 months: "I think I have a stronger faith in the future, so-called, and it seems to be better now." $(15 \mathrm{~A})$

After $2 \frac{1}{2}$ years he was more careful when expressing his expectations of recovery:

"Yes, I suppose you think less and less about it and realize that you're like this and it doesn't seem like it's going to work out much better. But to fully accept it is hard, you can put it out of your mind for a while but then the thoughts come again, why you can't walk properly.” (15B)

All informants mentioned one or several problems, such as: unhealed ulcers, intermittent claudication and altered sensations from the leg. Restricted mobility was however, accepted as a normal part of daily life thanks to adaptation and adjustment over time. Moreover, the use of different aids such as walking sticks and walking frames were accepted and appreciated. Some informants were told that nothing more could be done in terms of medical treatment, which meant that the only choice was to accept facts and learn to live with them. One man 
described during the interview after 6 months an ongoing slow recovery process with

remaining circulation problems:

"Yes sometimes it burns here in front but it is not so bad that I can't manage it and I'm walking better and it's disappearing slowly because I notice that it's getting better and I can now stand flat on the floor which I couldn't do before and I have to have the crutches, so it's slowly going forward.” (2A)

By the time of $2 \frac{1}{2}$ years he had adapted and accepted to live with his remaining problems:

"Yes it is bursting now. Yes I can get up and walk a little and so on. Yes, I have to live with it. It's sleeping now here and it gets cold, like, but when I'm moving the circulation is better. So I see that I'm never going to get rid of it but I can live with it because it doesn't hurt in that way that it did before the operation. Then I was in real pain.” (2B)

\section{Revealing other ailments}

When major relief from the symptoms of PAD was achieved other ailments were revealed. It appeared that the informants instead shifted focus towards other problems, which had been of secondary importance during the acute phase of PAD. When the pain gradually relieved and the ability to move and walk was improved, new or existing symptoms were described, affected by other illnesses as well as by the underlying vascular disease. The severe ischaemic pain concealed other ailments such as cardiac symptoms and musculoskeletal pain, which were disclosed during the recovery period.

"Yes, like, when I had the worst pain in my leg then I didn't think so much about my back because it took it away a little of it. Now it's my bloody back and hips that are hurting me most.” (15B)

"I got pain and had difficulties breathing and things like that but now I've got diuretic medicine and I think it has helped me....... Of course there are still problems with sleeping now because I have to get up at night and pee because I take diuretics.” (8B)

\section{Recapturing control over life}

By learning to live with the restrictions caused by the remaining problems of PAD and being able to plan and organize activities in daily life, these restrictions became more acceptable and 
a sense of normality was created. Trying to do the best to prevent further deterioration was important to gain a sense of control. However, being able to keep up with things and maintain independence in life was very much a result of hard work. From the descriptions of how to find routines in daily life and being encouraged in order to gain control over life, the following sub-themes emerged: fighting not to become worse, fighting against dependency

\section{Fighting not to become worse}

Realizing over time that the condition probably was not going to become better made the informants focus on at least not getting worse. A wish to never again end up in a situation like the one before treatment was a strong motive for lifestyle changes. Adopting a healthy diet and giving up smoking became important. Walking, cycling or keep-fit exercises were also important to various extents for all the informants, however, the motivation was higher during the interview after six months. One man described how eager he was to start exercising at that time:

“Well, now I’ve been having physiotherapy for one year, or for two years I think and now I am going to ask to go there again. I have been out of practice with it.” (7A)

The feeling that improvements were decreasing little by little over time was mentioned as one reason for the lower motivation over time. The same man said during the last interview after 21/2 years:

"Then there's the fact that the bed is so nice, yes, and in the beginning I went training but you get tired of it when it doesn't show any great results, no.” (7B)

Uncertainty and fear of doing something wrong affected the exercise at the beginning after treatment, but over time the training became more of a routine and the informants said that they knew what to do. One way to gain control in life was to assume the expert role regarding handling medicines, bandaging wounds and seeking information about PAD. 
Fighting against dependency

A majority of the informants had become dependent on different kinds of help and support.

Being dependent was experienced as something hopefully temporary six months after

revascularization. One woman described how she manages to clean the house by sitting on an office chair with wheels and how she thought this worked rather well.

"Yes I have this chair I sit on. The cleaning is as might be expected but it doesn't matter so we do a thorough cleaning a couple of times a year instead.” (10A)

However, during the last interview after $2 \frac{1}{2} 2$ year being dependent was accepted and often not even experienced as dependency. The same woman said, after $2 \frac{1}{2} 2$ years, how she had been forced to accept having a cleaner to help them.

"It is of course a big house but now we have a home help or a cleaner to be exact from a cleaning company who comes and cleans for us so I could be spared that. It got too much. I find it very hard to let some stranger in so it was very hard to accept help with the cleaning but there's no problem now, it works very well.” (10B)

All informants, except one, were living with a spouse who helped and supported them. A change of role function resulted however, in feelings of frustration and helplessness, when spouses and children had to take on many of the informants’ previous tasks. Moreover, thoughts of what would happen, if the spouse became overstrained or ill, occurred to them and meant a future threat. Arranging the distribution of work in the household and doing as much as possible to establish a sense of being useful was very important.

"Yes it works as long as she can keep up and we feel at home here (cries a little) but it has worked out this far. We have been talking about selling the house and moving. Yes, it doesn't cost much to live here and an apartment costs huge amounts. Then we have thought about getting help for the garden when my wife can no longer manage. She has painted the garage and, yes, she has done everything." (20B)

\section{Reappraising meaning in life}

Living with PAD over a long period meant reappraising meaning in life. Being patient and taking each day as it comes made it easier to handle adversity, and by lowering one's demands it was possible to avoid disappointments in the future. In the interview six months after 
revascularization a majority were still fighting against PAD, but during the last interview after $2 \frac{1}{2}$ years they realized that they had to accept and live with the disease. Realizing the meaning of getting old was a common statement, emphasized as a reason for limitations in daily life. The texts revealed a wish to live in peace and quiet the more time passed after the vascular treatment. The following sub-themes emerged from the narratives about reappraising life: making the best of the situation, developing new values in life.

\section{Making the best of the situation}

The interpretation of the texts was that becoming more familiar with the unfamiliar situation meant learning how to handle restrictions in life in a way that made it possible to move forward and make the best of the situation. One man said during the interview after six months how he now could help in the household and in the garden by taking his time and sitting instead of standing.

"But now when I can do things myself I have even vacuumed here. And it was two years since I last did that. Yes, and this has not been the only time. And I take care of things outside too. I sit on a stool and water, so it's possible, and I can stand up too but I sit down and cut the edges.” (2A)

After $2 \frac{1}{2}$ years he told about the new terrace that covered the greater part of the garden, which markedly had reduced his workload. He was very pleased with this solution.

"Yes and that's why I asked for that too, I couldn’t manage to cut the lawn and have the flowerbeds, so it's easier to have some potted plants to water, and then we have more out of it too, so my active life has become worse but that doesn't mean that it's a disaster.” (2B)

It became necessary to decrease pace in order to be able to live a fairly active life. The informants also had to accept that different tasks took longer to perform and could not be speeded up. Adapting to the situation by lowering expectations and being realistic in setting goals made it possible to feel satisfaction in life in spite of everything. 


\section{Developing new values in life}

By going through the hard time during the acute phase of PAD and the time passed after the revascularizations, new values in life were developed. The social life was still very important; a phone call could be as much appreciated as a personal meeting. Listening to dance music could give almost similar feelings of pleasure as real dancing had done before. Thinking that the situation could have been much worse and that there are others who are in a worse situation, made it easier to appreciate life as it was. Citing age as the main reason for the different ailments made it possible to view life as normal since ageing was seen as a natural part of life.

"I am really pleased every time I can get up and walk down the stairs and put some coffee on. It is wonderful, no, no, so I can, you know. I don't go down and sit in a corner and cry every day. That wouldn’t make it any more fun.” (4B)

"Well, it's the age too, you notice that you're not 25 any more, but as I say, you have to be pleased because there are those who are worse off.” (13B)

\section{INTERPRETATION AND DISCUSSION}

The long-term experience of living with PAD and the recovery following revascularization was interpreted as gradually becoming aware of having a chronic disease. There were constant interactions between becoming aware of the chronic nature of PAD and becoming better but not cured, recapturing control in life and reappraising meaning in life. All themes were interwoven, illuminating the transition from being in an acute phase of PAD towards the recovery after revascularizations and the entering into a chronic phase (Figure 1). Becoming better but not cured meant beginning to feel better but also to learn to live with remaining circulatory problems in the legs and a revelation of other ailments. It was necessary to fight deterioration and dependency to be able to recapture control over life. As time passed a 
reappraisal of meaning in life was visible as the informants tried to make the best of the situation and developed new values in life.

\section{Methodological considerations}

In qualitative research the concepts of credibility, transferability, dependability and conformability have been used to describe various aspects of trustworthiness (Lincoln and Guba, 1985). To ensure credibility, a sufficient amount of time was devoted to the interviews to understand the context of the participants. All interviews were conducted by the same interviewer and performed as similarly as possible. No member checking was carried out after the data collection and analyse although, an ongoing informally check with the participants was made during the interviews to clarify the data.

To strengthen the dependability, three authors (CWH, RK, EA) immersed into the data independently. New interpretations and insights were compared and discussed in an open dialogue and together with the second author (IRH) a mutual agreement of the categorizing process was reached. Furthermore, to make the findings more understandable; representative quotations from the transcribed texts were used.

There could be a threat to transferability since the participants were selected from a purposive sample, all of which were interviewed before the initial revascularization (WannHansson et al., 2005); this therefore, does not reflect patients who have undergone a vascular treatment as a whole. However, since the participants had various experiences from different treatment methods with different outcomes and represented both men and women with an age range from 61-85 years, this should increase the possibility of shedding light on the research question from a variety of aspects.

There is a risk that the authors knew too much about the phenomenon under investigation (van Manen, 1997). The first author's pre-understanding of the content of the 
texts was due to her previous experience as a nurse at a vascular surgical unit, however, the encounter with the participants was in the capacity as a researcher. In an attempt to limit the risk of pre-determined interpretation and increase credibility, a consistent method throughout the research process was used, with the analysis focused on the text and using other researchers in the process of analysis (Downe-Wamboldt, 1992).

\section{Discussions of the findings}

The findings showed that the participants gradually become aware of having a chronic disease and their expectations about recovery and the benefits of revascularization was initially often rather unrealistic. This meant that at the time as they began to feel better they also had to learn to live with remaining circulation problems in their legs, and to realize that they were not going to further improve. Similar results have also been described in patients having coronary artery disease who were interviewed before and after a coronary bypass; the expected benefits were often unrealistic and at odds with the documented evidence of the benefit of this procedure (Lindsay et al., 2000). The documented evidence regarding the outcome after revascularization has shown a decreasing long-term functional status, and many patients require continued and repeated treatments for the rest of their lives (Nicoloff et al., 1998; Landry et al., 2002, Wann-Hansson et al, 2005) The findings in the present study confirm that vascular interventions should be considered palliative and that patients have to learn to revise their expectations over time and be realistic about possible benefits. Accurate preoperative information is needed regarding the risks and benefits of vascular intervention and underlying atherosclerosis. Such information seems vital to assist patients and their families in accepting the chronic disease over time and to aid them in finding ways to live their life as normal as possible. 
Important benefits from revascularization were pain relief, ability to sleep and increased mobility. These symptoms did, however, camouflage other ailments. It is well known that PAD patients have extensive comorbid conditions, which could restrict activities in daily life (Crouch et al., 2001; Nehler et al., 2003). It is also known that the elderly are more likely to become functionally impaired and use a much greater proportion of acute and long-term care resourses (SCB, 2001). The fact that a majority of PAD patients are elderly could, therefore, be a reason for a decreased physical function, and many participants mentioned age as one reason for their ailments. This emphasizes the importance of having a comprehensive view in the care of this group of patients and to be aware of other diseases and problems in daily life besides PAD. Thus, one important task is to assess PAD patients carefully to identify risk factors predictive of future disability, that can be modified so that interventions can be implemented to prevent further deterioration.

To be able to live with PAD over a longer time it was necessary to adapt and accept restrictions in daily life and to shift focus from loss and burden towards health within illness and normality. This process could be seen in the light of the concept of transition and several essential properties of the transition process have been identified: awareness, engagement, change and difference, time span, critical point and events (Meleis et al., 2000). Awareness was illuminated when the participants became aware of having a chronic disease and realized that they were not going to get much better. Identifying the possibility of organizing daily activities in new ways was pivotal for a sense of independence, and fighting not to becoming worse was examples of engagement. All transitions involve change, and the participants moved from an acute illness experience to chronic illness and a majority also from chronicity to a new wellness. Confronting differences was exemplified by how the participants reappraised their values in life. The time span ran from the first signs of PAD to treatment and recovery. Time of treatment and hope of recovery, and fluctuation periods with good and bad 
days and finally a sense of stabilization over time with new routines, skills, lifestyles and selfcare activities could be identified as critical points and events. According to Meleis \& Trangenstein (1994), the completion of a transition is when a person has reached a period of less disruption or greater stability through growth, relative to what has occurred before. Therefore, it is important to identify and support effective coping strategies, which could facilitate successful transitions and a sense of well being for patients with PAD. Interventions such as information and education about the underlying atherosclerotic disease and PAD could promote the patient's capacity for self-management and prevent unhealthy transitions. The fluctuating nature of PAD suggests that these interventions should be performed over a longer time and both specialized vascular clinics and primary health care should be involved. However, further research of the content and extent of such information and education programmes and possible outcome is needed.

Despite remaining ailments after the revascularizations, this state was preferable to the acute period with severe pain. Comparing between past and present and with other people who were in a worse condition was a common way to put the present situation in a favourable light. This way of maintaining a sense of self and well-being has been described as downward comparison, which assumes that subjective well-being can be enhanced through comparison with less fortunate others (Wills, 1981). Studies have shown that both upward and downward social comparisons could serve as an adaptive function. Frieswijk et al. (2004a; 2004b) showed that identifying oneself with others doing better and to contrast oneself with others doing worse was positively related to life satisfaction among elderly persons. The use of downward comparisons in this study was common after both 6 months and 21/2 years and may have helped to protect the patients by minimizing the impact of the PAD on their lives. This knowledge could be helpful to enable patients with PAD to interpret their situation more positively during a course of education and exercise programmes. 
Living with PAD over a longer time meant an ongoing fight not to become worse and dependent. However, this fight was not carried out alone, and considerable efforts by close relatives were necessary to keep the feeling of independence. Chronic disease makes unique demands on the patient and their family. The health illness transition could not be isolated from the family and changes in family situations have been conceptualized as situational transitions when family members transition into a caregiving role (Schumacher and Meleis, 1994; Meleis et al, 2000). In the present study all participants except one lived with a spouse and together they worked to meet the demands in daily life. Role reversal occurred commonly, with the spouse or children taking on many of the participant's previous role tasks. These findings suggest that the transition process also includes the family and/or significant others, which indicates the importance of involving them in information and education efforts. Support directed to both patients and their relatives may increase knowledge and confidence, which could delay or avoid hospital admissions and facilitate transitions towards health and a perception of well-being. However, further research regarding PAD patients and their carers' needs is required.

\section{CONCLUSION}

The long-term experience of living with peripheral arterial disease means becoming aware of having a chronic disease and where the adaptation process seemingly plays an important role for the achievement of stability and less disruption. The findings showed that revascularization offers several benefits for patients with PAD. However, several critical points and events such as other concurrent diseases, unrealistic hope for recovery and the complex course of PAD and atherosclerotic disease complicated the transition process towards health and well-being. Thus, information and education may be important 
complementary interventions for patients with PAD, which can affect quality of life in a positive direction and facilitate a healthy transition. However, further research regarding development and implementation of clinical practice guidelines including structured information and education is needed.

\section{Acknowledgements}

The Lori Lindahl Foundation, The Swedish Order of St. John and the Department of Nursing Science, Lund University, the Vårdal Institute, the Swedish Institute supported this study for

Health Sciences, Lund, and the Department of Vascular Diseases, Malmö University Hospital. 


\section{REFERENCES}

Abou-Zamzam, A.M., Lee, R.W., Moneta, G.L., Taylor, L.M., Porter, J.M., 1997. Functional outcome after infrainguinal bypass for limb salvage. Journal of Vascular Surgery, 25, 287297.

Berg, B. L., 2001. Qualitative research methods for the social sciences (4th ed.), Allyn and Bacon, Boston, pp. 238-267.

Chetter, I. C., Spark, J.I., Scott, D. J., Kent, P. J., Berridge, D. C., Kester R. C., 1998. Prospective analysis of quality of life in patients following infrainguinal reconstruction for chronic critical ischaemia. British Journal of Surgery 85, 951-5.

Chick, N., Meleis, A, 1986. Transitions: a nursing concern, Chapter 18. In Nursing research methodology (Chinn P. ed.), Gaithersburg, Aspen, pp. 237-257.

Crouch, D. S., McLafferty, R. B., Karch, L. A., Mattos, M. A., Ramsey, D. E., Henretta, J. P., Hodgson, K. J., Sumner, D. S., 2001. A prospective study of discharge disposition after vascular surgery. Journal of Vascular Surgery 34, 62-68.

Dormandy J. A., \& Rutherford R. B., 2000. Management of Peripheral Arterial Disease (PAD). TransAtlantic Inter-Society Consensus (TASC). European Journal of Vascular and Endovascular Surgery 19 (suppl A), 1-244. 
Downe-Wamboldt, B., 1992. Content analysis: method, applications and issues. Health Care for Women International 13, 313-321.

Frieswijk, N., Buunk, B. P., Steverink, N., Slaets, J. P. J., 2004. The interpretation of social comparison and its relation to life satisfaction among elderly people: does frailty make a different? Journal of Gerontology 59 (5), 205-257.

Frieswijk, N., Buunk, B. P., Steverink, N., Slaets, J. P. J., 2004. The effect of social comparison information on the life satisfaction of frail older persons. Psychology and Aging 19 (1), 183-190.

Gibson, J. M. E., Kenrick, M., 1998. Pain and powerlessness: the experience of living with peripheral vascular disease. Journal of Advanced Nursing 27, 737-745.

Graneheim, U.H., Lundman, B., 2004. Qualitative content analysis in nursing research: concepts, procedures and measures to achieve trustworthiness. Nurse Education Today, 24, 105-112.

Klevsgård, R., Hallberg, I.R., Risberg, B., Thomsen, M.B., 2000. The effects of successful intervention on quality of life in patients with varying degrees of lower limb ischaemia. European Journal of Vascular and Endovascular Surgery 19, 238-245.

Klevsgård, R., Risberg, B., Thomsen, M. B., Hallberg, I. R., 2001. A 1-year follow-up of quality of life after haemodynamically successful or unsuccessful surgical revasculation of lower limb ischaemia. Journal of Vascular Surgery 33, 114-122. 
Koch, T., Kralik, B., 2001. Chronic illness: reflections on a community-based action research programme. Journal of Advanced Nursing 36 (1), 23-31.

Kralik, D., Koch, T., Price K., Howard, N., 2004. Chronic illness self-management: taking action to create order. Journal of Clinical Nursing 13, 259-267.

Kralik D., Visentin K., van Loon A., 2006. Transition: a literature review. Journal of Advanced Nursing 55 (3), 320-329.

Landry, G. J., Moneta, G. L., Taylor, L. M., Edwards, J. M., Yeager, R. A., Porter, J. M., 2002. Long-term outcome of revised lower-extremity bypass grafts. Journal of Vascular Surgery 35 (1), 56-63.

Lincoln, Y. S., Guba, E. G., 1985. Naturalistic inquiry. Sage Publications Inc, Newbury Park, California.

Lindsay, G. M., Smith, L. N., Hanlon, P., Wheatley, D. J., 2000. Coronary artery disease patients' perception of their health and expectations of benefit following coronary artery bypass grafting. Journal of Advanced Nursing 32 (6), 1412-1421.

Meleis, A. I., Sawyer, L. M., Im, E. O., Hilfinger, Messias D. K., Schumacher, K., 2000. Experiencing transitions: an emerging middle-range theory. Advanced Nursing Science 23 (1), 12-28. 
Meleis, A. I., Trangenstein, P. A., 1994.Facilitating transitions: redefinition of the nursing mission. Nursing Outlook 42 (6), 255-259.

Miller, J. F., 1992. Coping with chronic illness (pp. 3-18). F.A. Davis Company,V Philadelphia.

Mishler, E. G., 1986. Research interviewing: context and narrative. Harvard University Press, London.

Nehler, M. R., McDermott, M. M., Treat-Jacobson, D., Chetter, I., Regensteiner, J., 2003. Functional outcomes and quality of life in peripheral arterial disease: current status. Vascular Medicine 8, 115-126.

Nicoloff, A. D., Taylor, L. M., McLafferty, R. B., Moneta, G. L., Porter, J. M., 1998. Patient recovery after infrainguinal bypass grafting for limb salvage. Journal of Vascular Surgery 27, 256-266.

SCB Statistisk årsbok (Statistical Yearbook), 2001. Stockholm: Statistiska Centralbyrån.

Schumacher, K.L., Meleis, A.I., 1994. Transitions: A central concept in nursing. Journal of Nursing Scholarship, 26, 2, 119-127.

Selvin, E., Erlinger, T.P., 2004. Prevalence and risk factros for peripherl arterial disease in the United States. Circulation 110, 738-743. 
Thorsen, H., McKenna, S., Tennant, A., Holstein, P., 2002. Nottingham Health Profile scores predict the outcome and support aggressive revascularization for critical ischaemia. European Journal of Vascular and Endovascular Surgery 23, 495-499.

Treat-Jacobson, D., Walsh, M.E., 2003. Treating patients with peripheral arterial disease and claudication. Journal of Vascular Nursing 21, 5-14.

van Manen, M., 1997. Researching lived experience. $2^{\text {nd }}$ ed. The Althouse Press, Toronto.

Wann-Hansson, C., Hallberg, I.R., Risberg, B., Lundell, A., Klevsgård, R., 2005a. Healthrelated quality of life after revascularization for peripheral arterial occlusive disease: longterm follow-up. Journal of Advanced Nursing 51 (3), 227-35.

Wann-Hansson, C., Hallberg, I.R., Klevsgård, R., Andersson, A. 2005b. Patients’ experiences of living with peripheral arterial disease awaiting intervention: a qualitative study. International Journal of Nursing Studies 42, 851-862.

Wills, T., 1981. Downward comparison principles in social psychology. Psychological Bulletin 90, 245-271. 
Table 1. Demographic characteristics of the participants $(\mathrm{N}=14)$

\begin{tabular}{|c|c|c|}
\hline Characteristics & After 6 months & After $2 \frac{1}{2}$ years \\
\hline Age m (SD) & $75(6.8)$ & $77(6.8)$ \\
\hline Gender n (\%) & & $9 / 5(64 / 36)$ \\
\hline Male/female & $9 / 5(64 / 36$ & \\
\hline \multicolumn{3}{|l|}{ Cohabitation n (\%) } \\
\hline Living alone & $1(7)$ & $1(7)$ \\
\hline Living with relative & 13 (93) & $13(93)$ \\
\hline \multicolumn{3}{|l|}{$\begin{array}{l}\text { Self-reported circulation } \\
\text { problems in the legs } \mathbf{n}(\%)\end{array}$} \\
\hline Intermittent claudication & $5(36)$ & $7(50)$ \\
\hline Ischaemia rest pain & 0 & 0 \\
\hline Ischaemia ulcers & $5(36)$ & $4(28)$ \\
\hline $\begin{array}{l}\text { Altered sensations from the } \\
\text { legs }\end{array}$ & $4(28)$ & $3(22)$ \\
\hline \multicolumn{3}{|l|}{$\begin{array}{l}\text { Type of interventions during } \\
\text { the follow-up } \mathrm{n}(\%)\end{array}$} \\
\hline Endovascular intervention & $8(57)$ & $2(7)^{\mathrm{a}}$ \\
\hline Surgery & $3(21)$ & $2(14)^{b}$ \\
\hline Endovascular and surgery & $3(21)$ & \\
\hline Endovascular x2 and surgery & & $1(7)^{\mathrm{c}}$ \\
\hline \multicolumn{3}{|l|}{$\begin{array}{l}\text { Risk factors (self-reported) } \\
\text { n (\%) }\end{array}$} \\
\hline Smoking & $5(36)$ & $3(21)$ \\
\hline Hypertension & 13 (93) & $13(93)$ \\
\hline Heart disease & $6(43)$ & $7(50)$ \\
\hline Diabetes & $6(43)$ & $6(43)$ \\
\hline Stroke/TIA & $4(28)$ & $4(28)$ \\
\hline Kidney disease & $1(7)$ & $1(7)$ \\
\hline
\end{tabular}

\footnotetext{
${ }^{\mathrm{a}}$ One patient underwent in total endovascular $\mathrm{x} 2$ and surgery $\mathrm{x} 1$ and one patient underwent in total endovascular $\mathrm{x} 2$

${ }^{\mathrm{b}}$ One patient underwent in total endovascular $\mathrm{x} 1$ and surgery $\mathrm{x} 1$ and one patient underwent in total endovascular $\mathrm{x} 1$ and surgery $\mathrm{x} 2$

${ }^{\mathrm{c}}$ One patient underwent in total endovascular $\mathrm{x} 3$ and surgery $\mathrm{x} 1$
} 
Figure 1. Interpretation of the long-term experiences of living with peripheral arterial disease and recovery following vascular interventions and the transition to becoming aware of having a chronic disease.

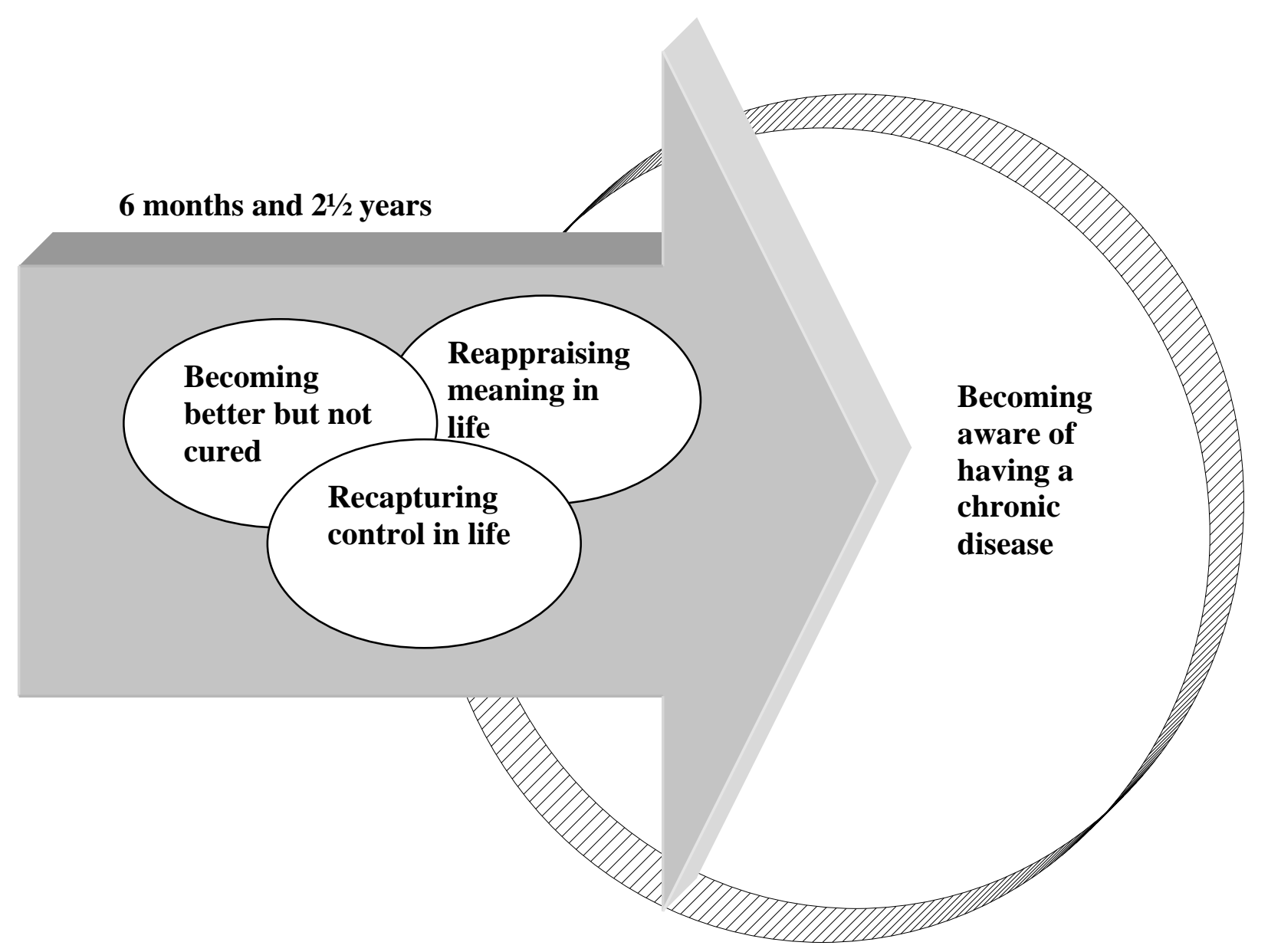

